\title{
السيناريو والتصميم المستقبلي التفاعلي "
}

إعلاد

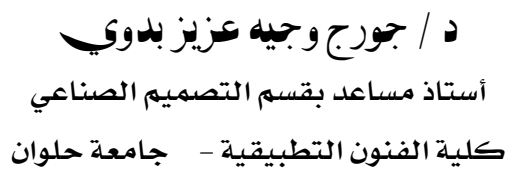


= = السيناريووالتصميم/المستقبلي التفاعلي 


\section{السيناريو والتصميم المستقبلي التفاعلي}

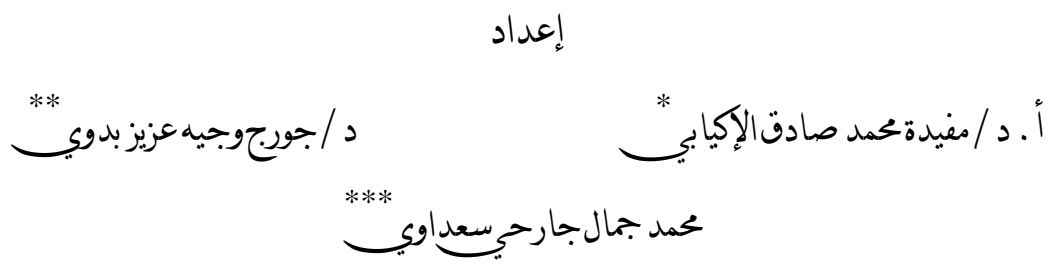

هلخص البمث

الدراسـات المستقبلية لها تقنيات (مناهج) من أهمها تقنيـة السيناريوهات المستقبلية يمكننـا

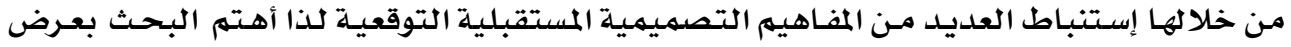

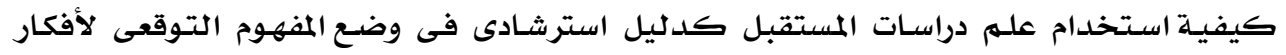

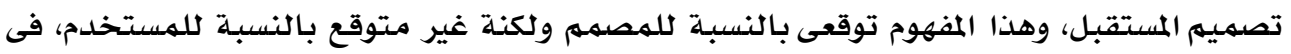
تلبية رغباته وطموحاته، أى تكون هذة المفاهيم مثيرة وغير تقليدية ويمكن تطبيقها فى المستقبل

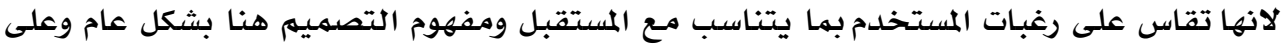

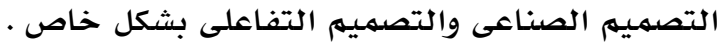

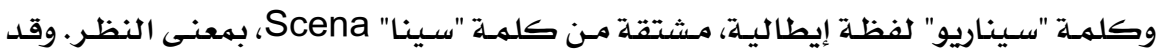

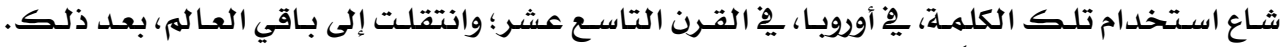

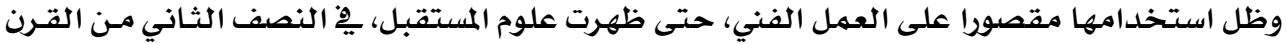

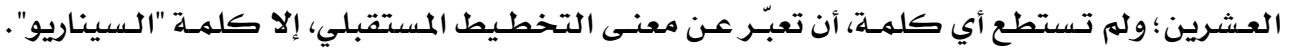

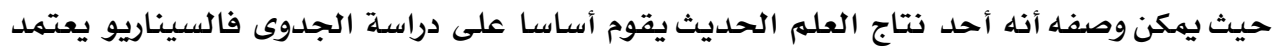

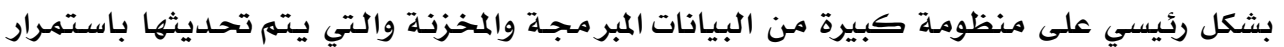

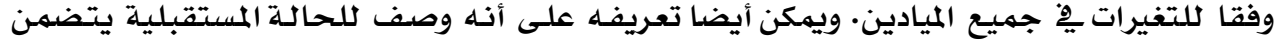

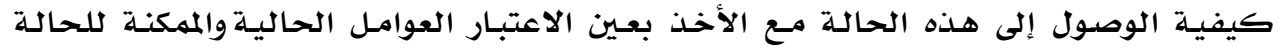

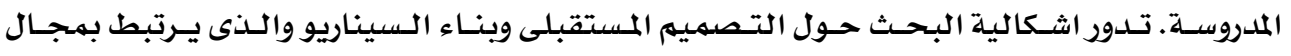

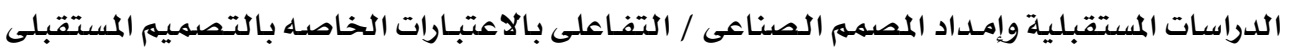

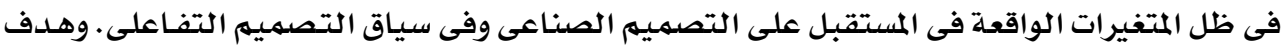

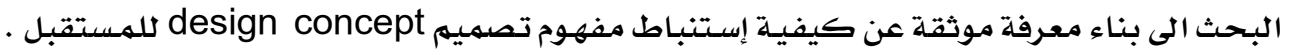

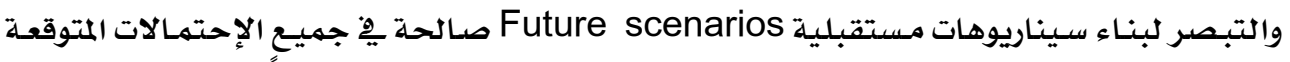

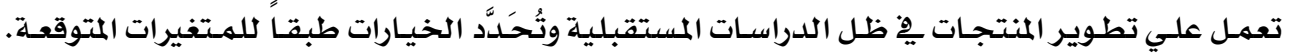

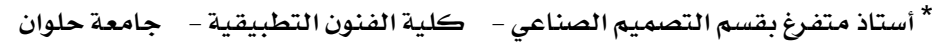

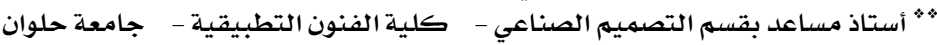

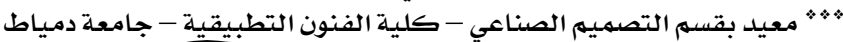




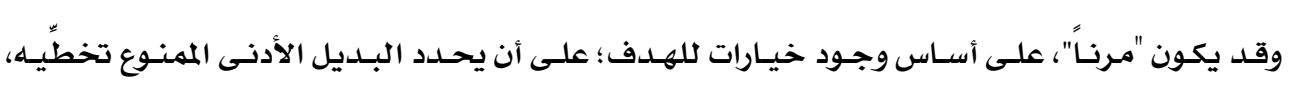

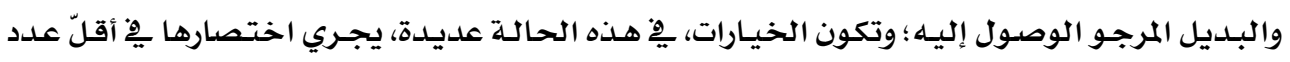

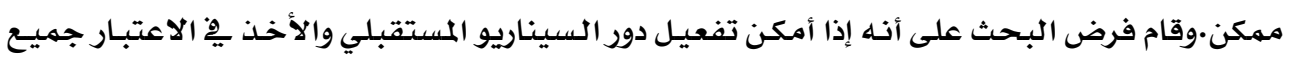

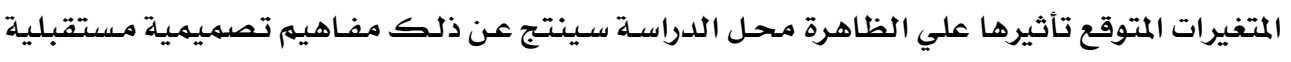

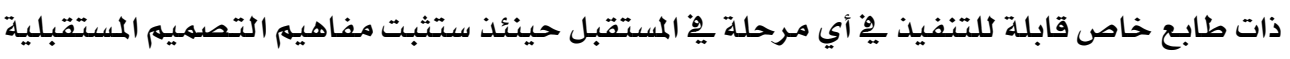

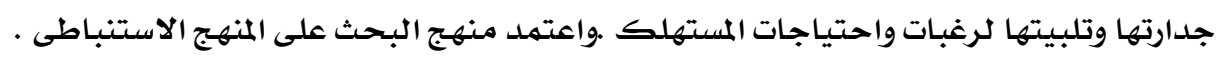
الكلمات الدالة :

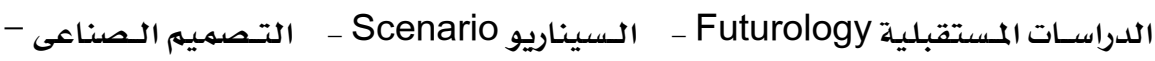

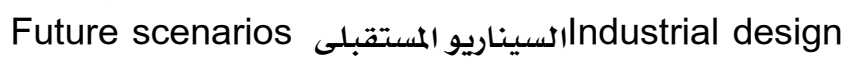

الاقدهمة:

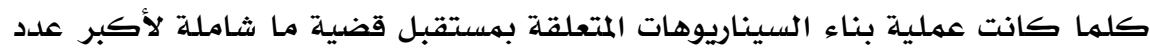

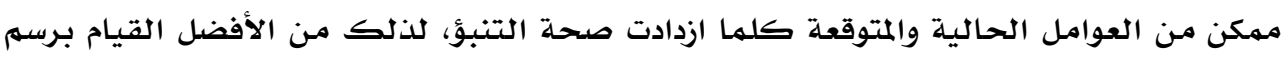

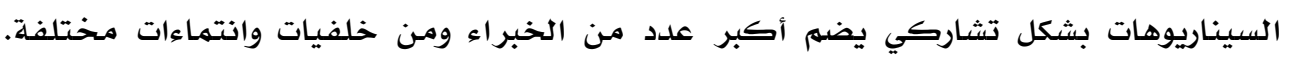

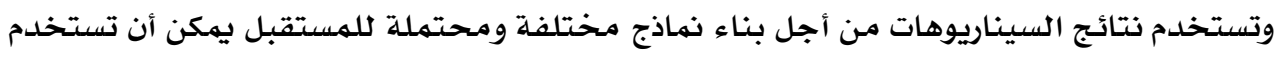

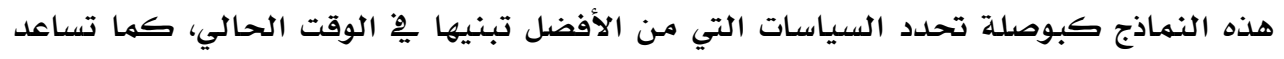

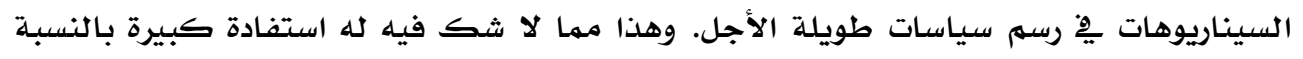

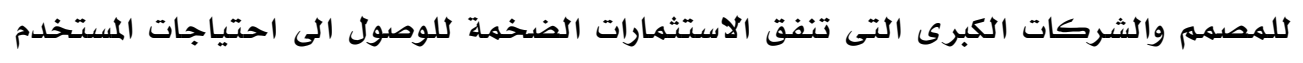

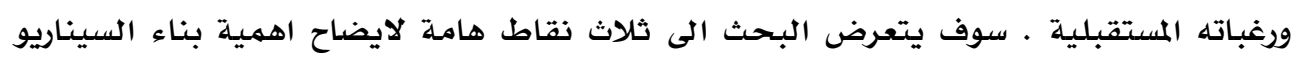

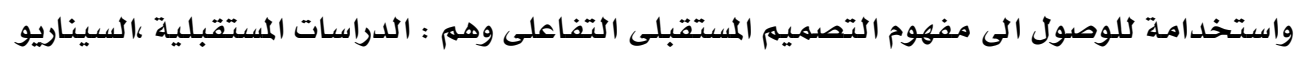

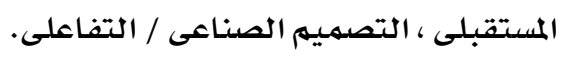

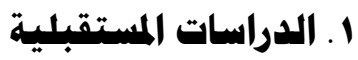

اـاـ أهمية اللدراسات المستقبلية :

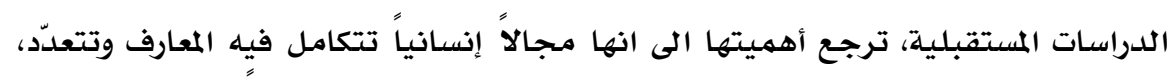

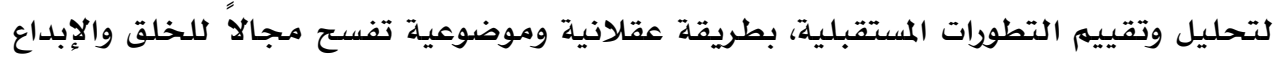

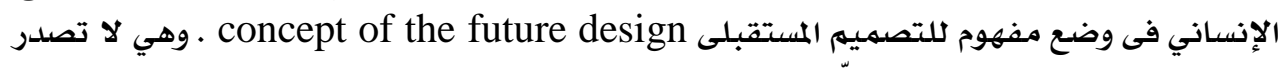

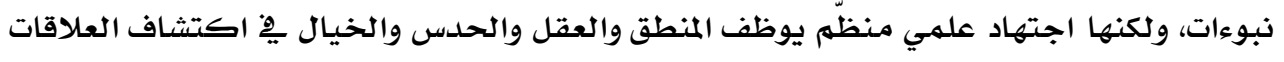

المستقبلية .شكل (1) 
مجلة بحوث التربية النوعية - علد بrاء - يوليو

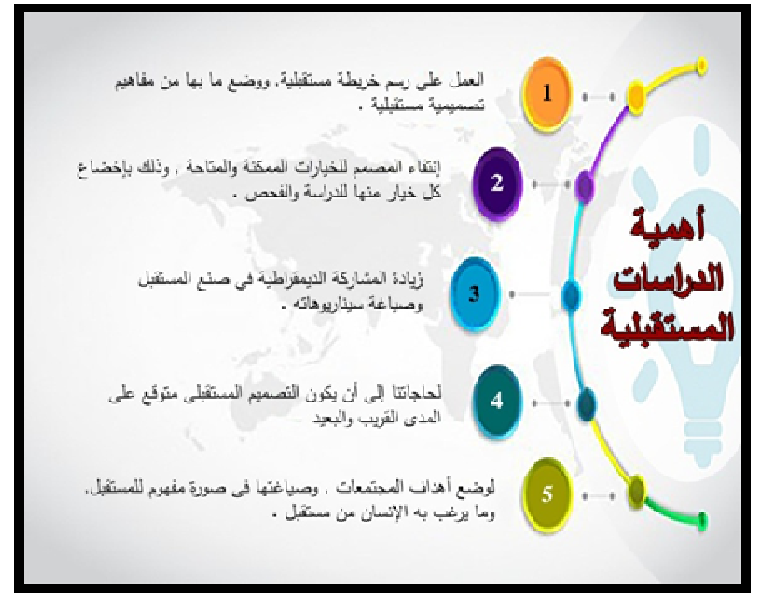

\section{ثكل (1) أهمية الدراسات المستقبلية}

إ_- خصائص الدراسات المستقبلية :

كتب الكثير مـن المنشخلين بـالدراسـات المستقبلية (المستقبليون) عن أهـم مـا يتميـز بـه هـذه

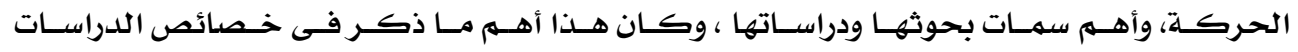

المستقبلية .شكل (r)

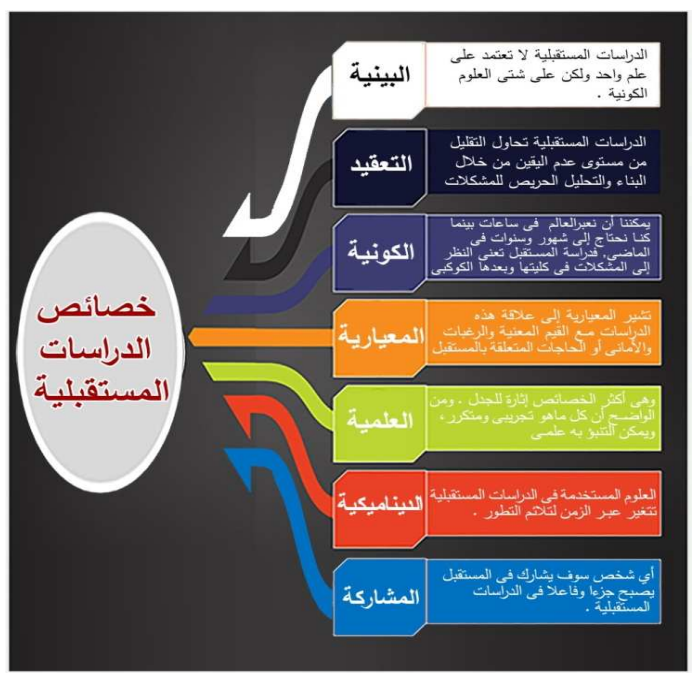

شكل (Y) خصائص الدراسعات المستقبلية

ا_rـ الهلدف من اللدراسات المستقبلية :

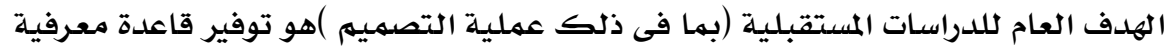

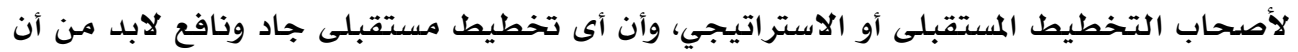


يسبقه دراسـة إستشرافية ، وأن الهدف من الدراسات المستقبلية ليس تقديم النبوءات ، ولكن تقديه

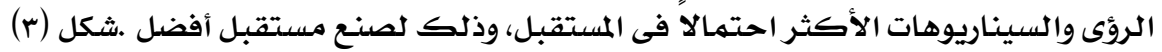

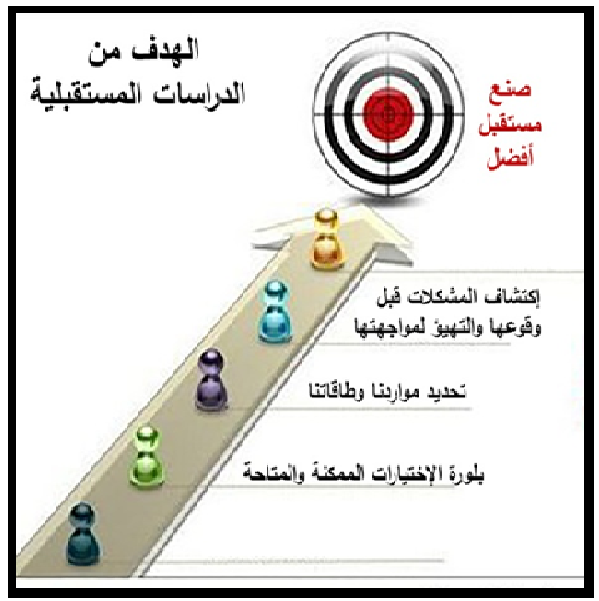

شكل (r) الهدف من الدراسات المستقبلية

ائـ أساليب الدراسات المستقبلية :

وعند النظر لأي عله أو فن نجد له أسلوب ومنهج خاص بـه، بدأ مـع بدايات العلهم وتطور معه

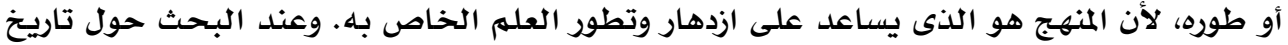

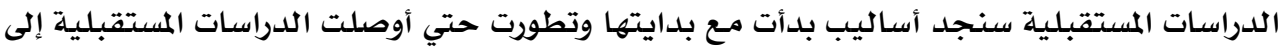

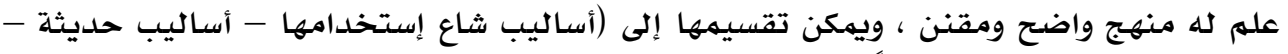

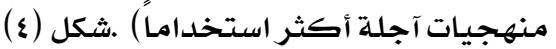

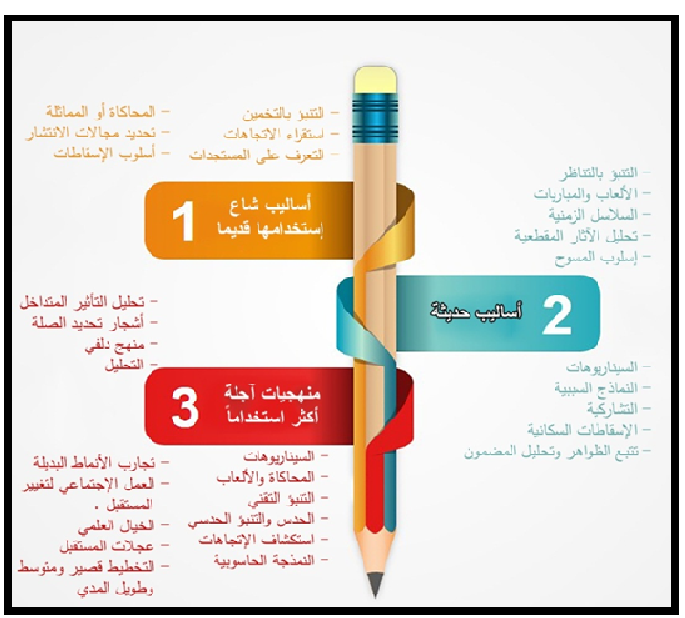

شكل (ع) أساليب الدراسات المستقبلية 
السيناريو هو كتابة تفصيلية لسير الأحداث للوصول إلي مستقبل جيد ومرغوب فيه،

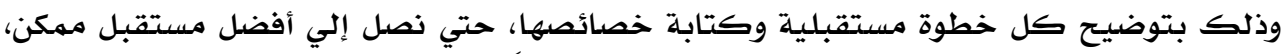

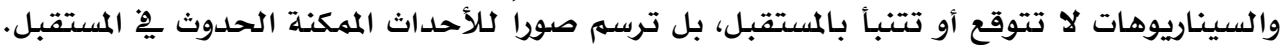
شكل (0)

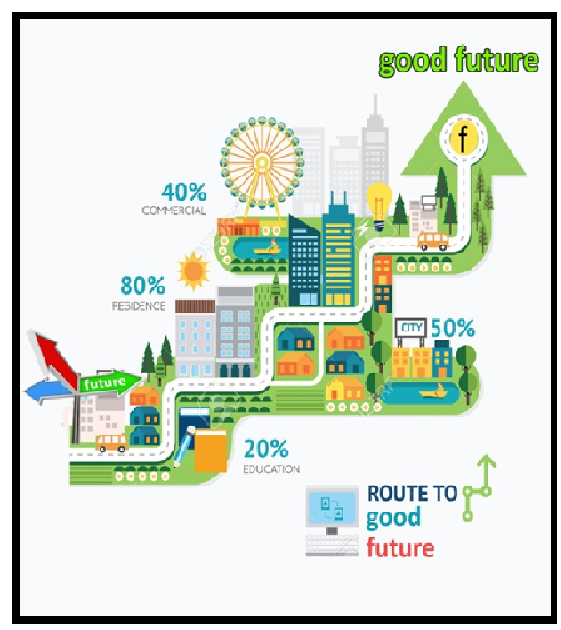

$$
\text { ثكل (0) مفهوم السيناريو المستقبلى }
$$

r.r. r. خصائص السيناريو المستقبلى :

- -

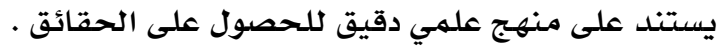

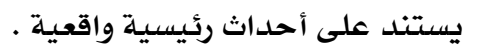
يقوم على تحقيق أهداف وطنية أو سياسية أو عسكرية أو اقتصادية" ، أو الوصدول إلى إلى أقرب مـا يمكن من هذه الأهداف" تحقيق أهداف عدد السيناريوهات يمكن أن يكون من اثنين إلى أربعة .

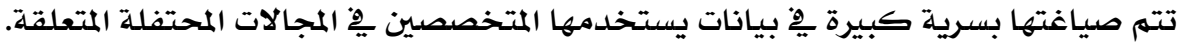
- يعتمد على حشد من العلماء والخبراء. r_r_ أنواع السيناريوهات المستقبلية :

السيناريوهات لها ثلاثة أنواع حسب تحديد العالم "جوديه Godet M " : - سيناريو مرجعي: يعبِّر عن الوضـع الأكثر احتمالاً، لتطور الظاهرة، محل البحث. 


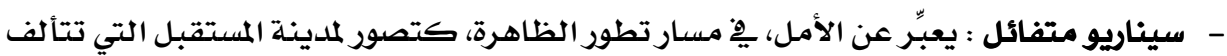

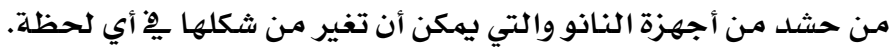

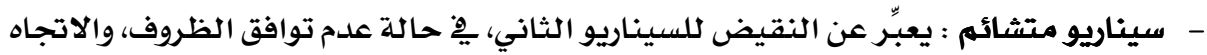

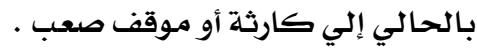

r.عـ أهداف السيناريوهات المستقبلية :

السيناريوهات المستقبلية هدفها تعزيز المعرفة بما تقدمه من فهم عميق يِّ نطاق الممكن،

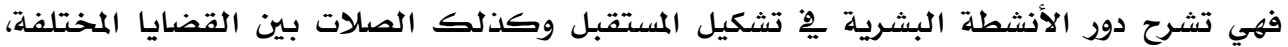

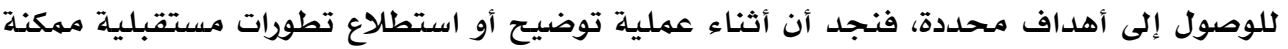

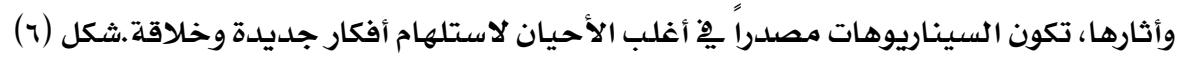

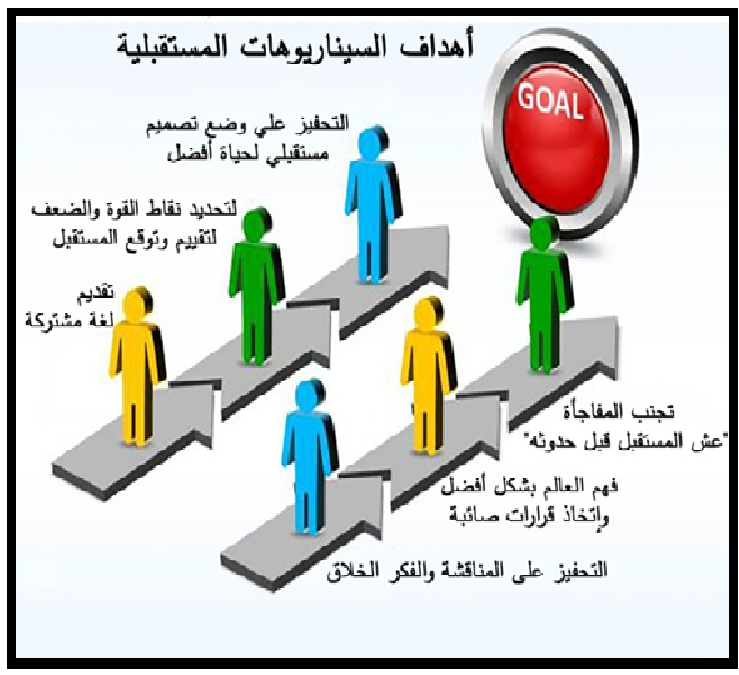

شكل (7) أهداف السيناريوهات المستقبلية

rــ أهمية السيناريوهات المستقبلية :

يوفر السيناريو المستقبلي وسيلة لترتيب التصورات حول ما يهكن أن يحمله لنا المستقبل

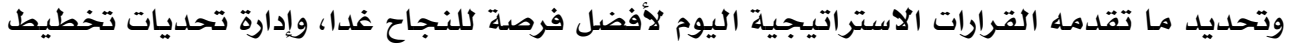

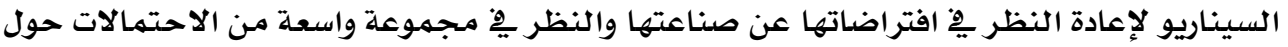

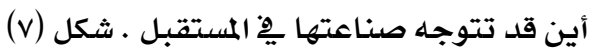




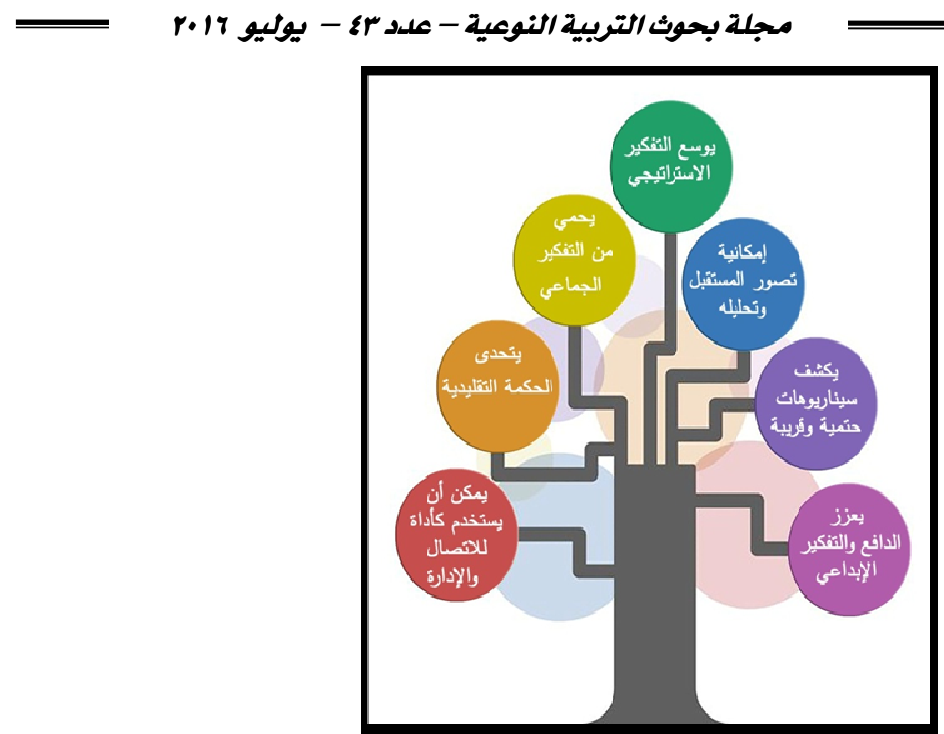

شكل (v) أهمية السيناريوهات المستقبلية

r.T - معايير جودة السيناريوهات المستقبلية :

هنالك عدة معايير يمكن استخدامها يِّ تقويم السيناريوهات المطروحة حول المستقبل

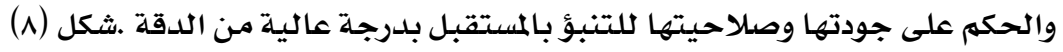

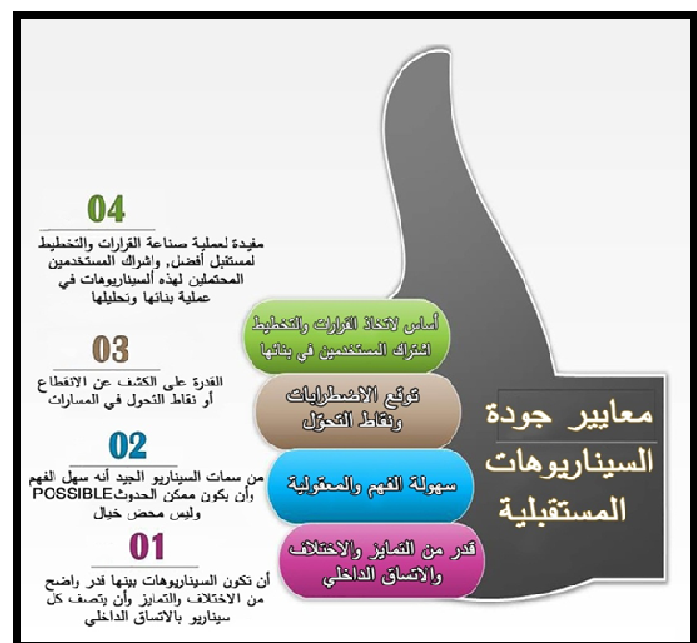

شكل (^) معايير جودة السيناريوهات المستقبلية

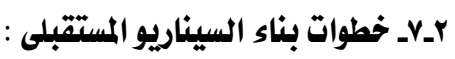

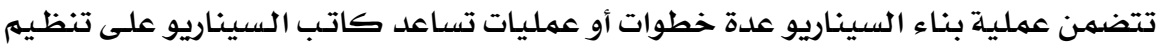

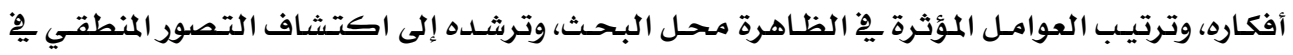


تتابع الأحسداث والتصرفات والوقوف على بعض العلاقات الحاكمهـة لمسار التطور، وتقوده إلى حصر

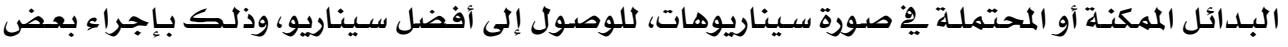

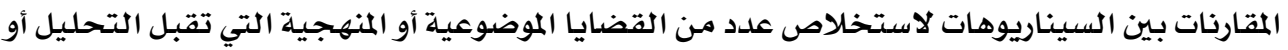
التطوير، أو الاكتفاء بتحليل مقارن للسيناريوهات مـع التركيز على متطلبات كل منهات التها لشكل (17)

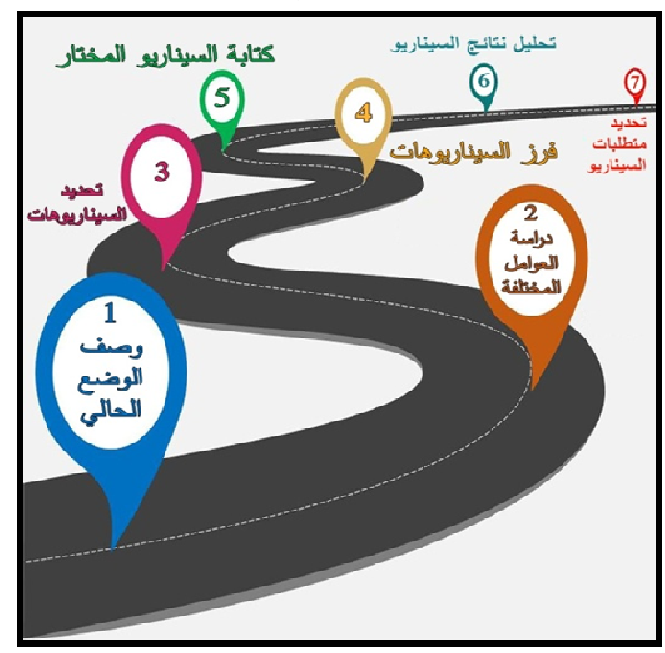

$$
\text { شكل (19) خطوات بناء السيناريو المستقبلي }
$$

r. التصميم الصناعى / التفاعلى :

ץ- The Design التصميم

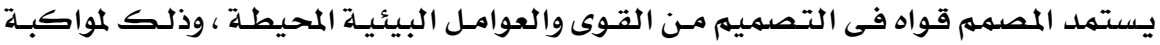

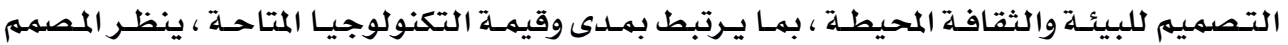

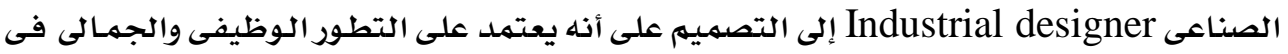

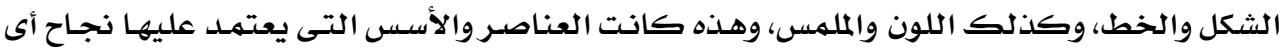

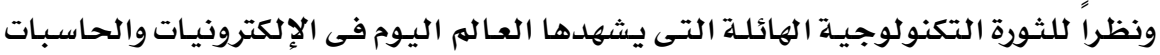

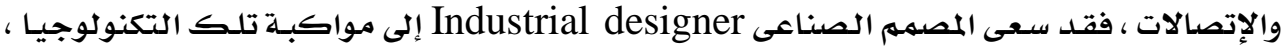

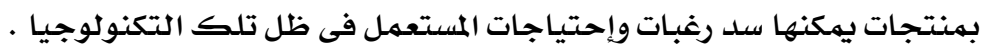

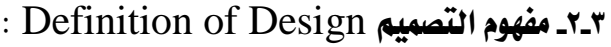

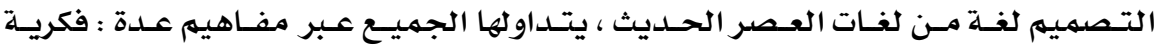

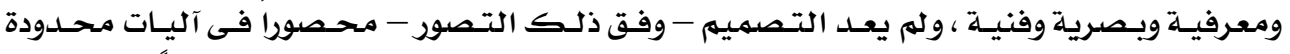

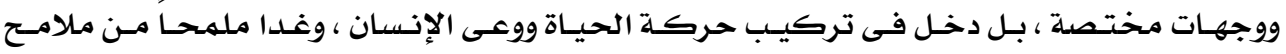

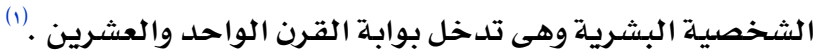


فالتصميهم هو عمل ذهني أكثر منـه عمل عضلي عضوي ، فهو عبـارة عن عمليـة منظمـة

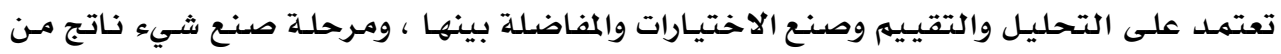

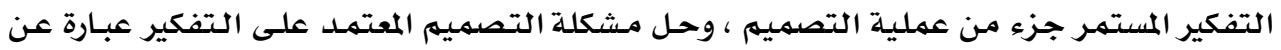

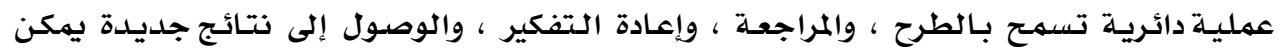

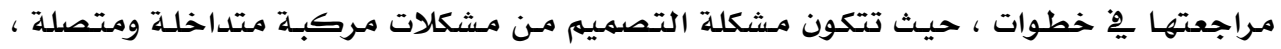

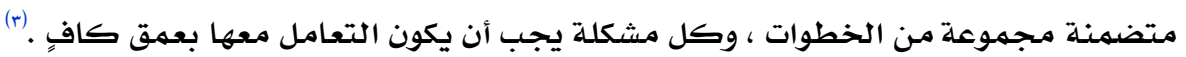
ويري جونز Jones ما اعتبره التعريف النهائي Ultimate definition للتصميم بأنه

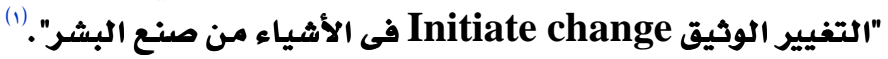

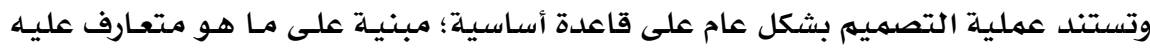

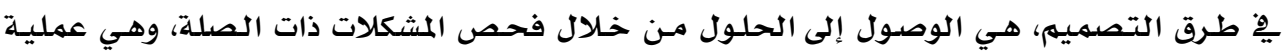

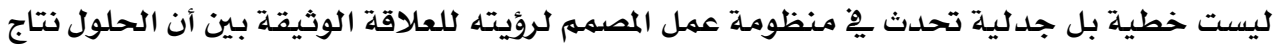

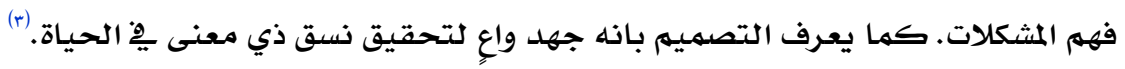

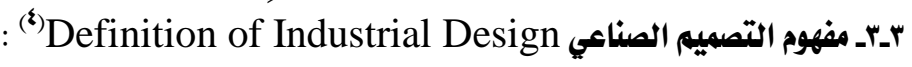
على الرغم مـن أن فلسفة المنتجج الذكي في أواخر القـرن العشرين تضمنت بجانب الأبعـاد

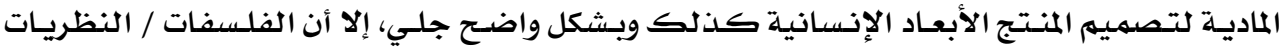

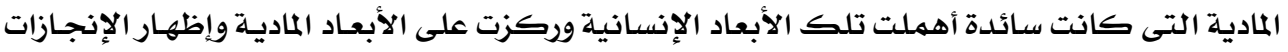

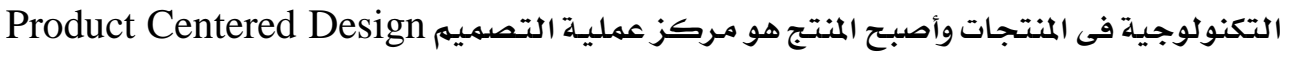

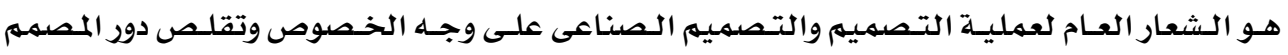

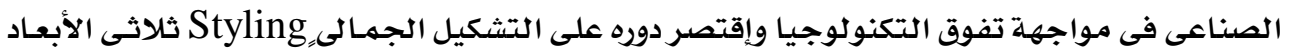
3D نلمنتجات الذكية .

وكان المفهوم السائد للتصميم الصناعى فى الألفية الثانية(القرن العشرين) هو "أنه نشاط

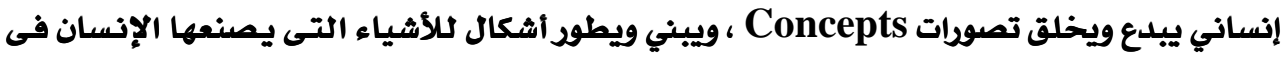

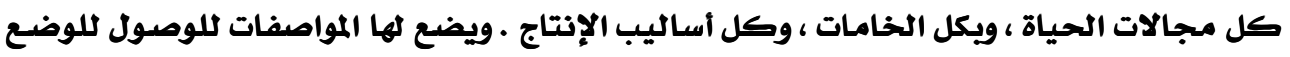

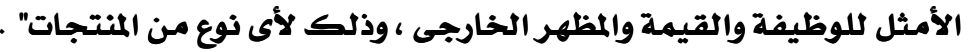

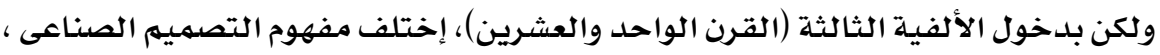

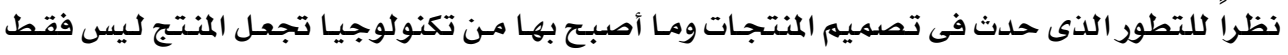

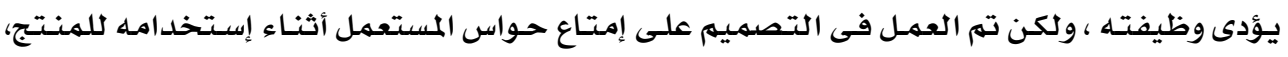

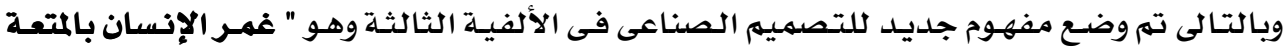

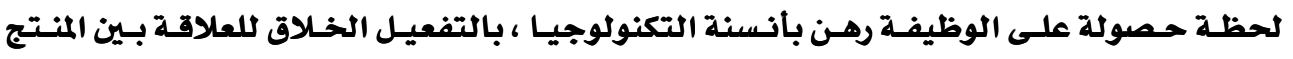
التكنولوجي وبين الإنسان ، بتصميم الإحساس به الوطيفة وهانسية العاطفة للإنسان" . 
يشير لاوسـون Lawson إلى أن عمليـة التصميم تتألف مـن مـراحل ثلاث هي : (التصور

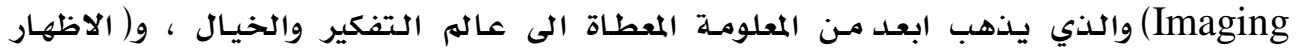

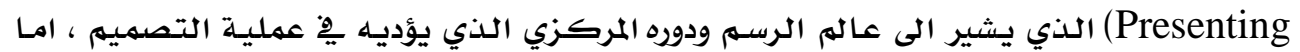

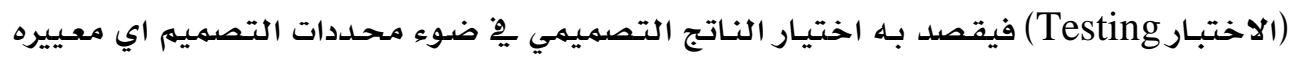

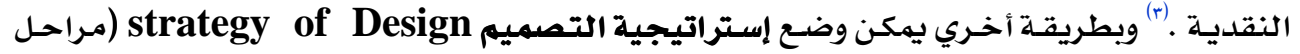

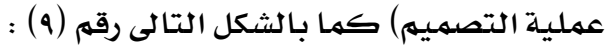

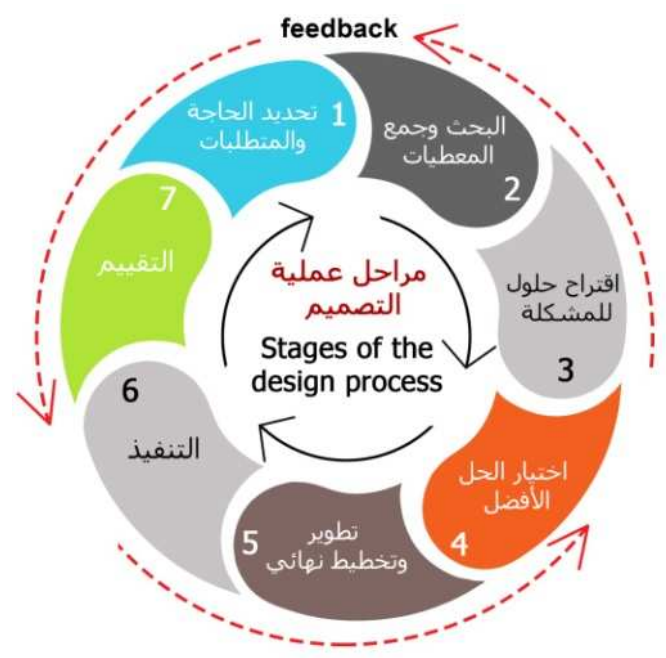

ثكل(ه) مراحل عملية التصميم

rــ التصمييم التقاعلي :

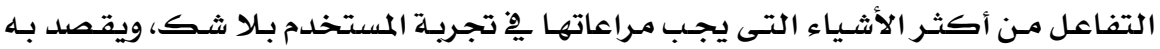

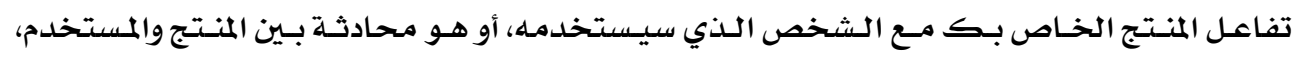
وكلما تكون المحادثة مهلة كلما يبتعد المستخدم عن المنتج ويقترب لمنتج مـثير للإهتمام أكثر، هـذا

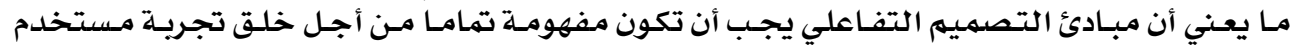
أكثر فعالية، . . إذا مـاهو التصميهم التفاعلي ؟ هو عملية يتم فيها توصيل العالم الرقمي إلى العالم البشري، أى تجعل الأثياء على الموقع او التطبيقات سهلة الاستخدام بالنسبة للمستخدم. (v)

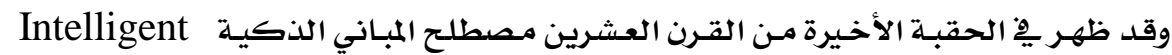

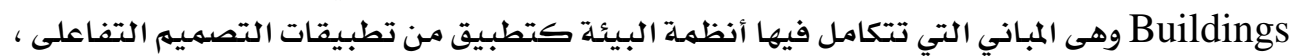

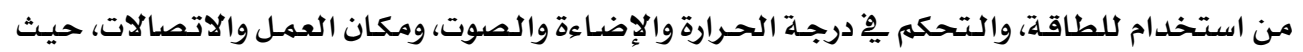

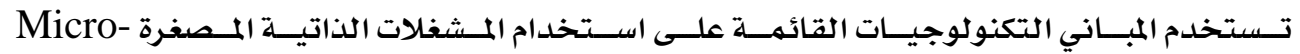
processors 


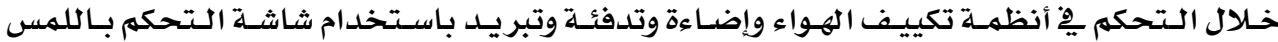
Touch screen automation Sensors

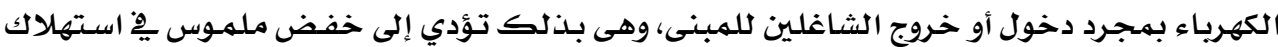

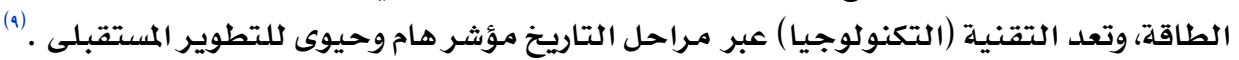

\section{r_t خطوات التصميي المستقبلى}

من خلال البناء المعربِّ لدور الدراسات المستقبلية ِِّ بناء السيناريو المستقبلي قد توصل

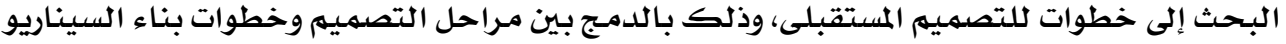

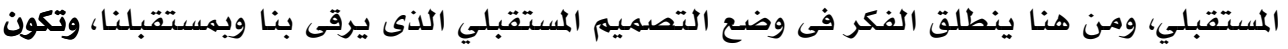
نتائج البحث كالتالي :

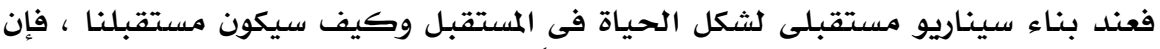

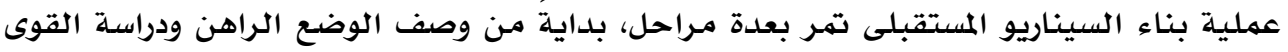

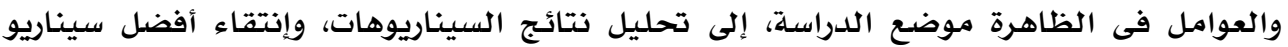

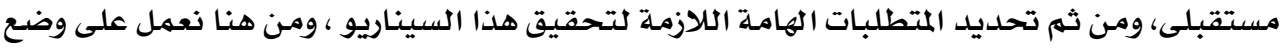

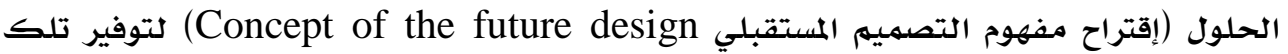
المتطلبات اللازمة ، ثم إختيار الحل الأفضل (مفهوم التصميهم المستقبلى الأفضل)، ووضع هذاح التها الحل

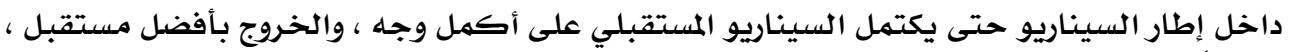

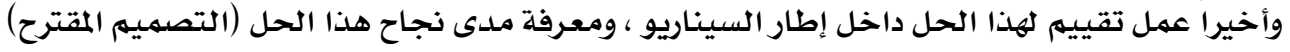

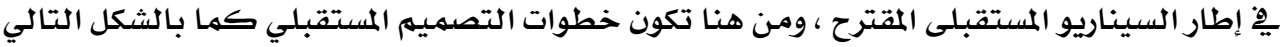
رقم (IV) :

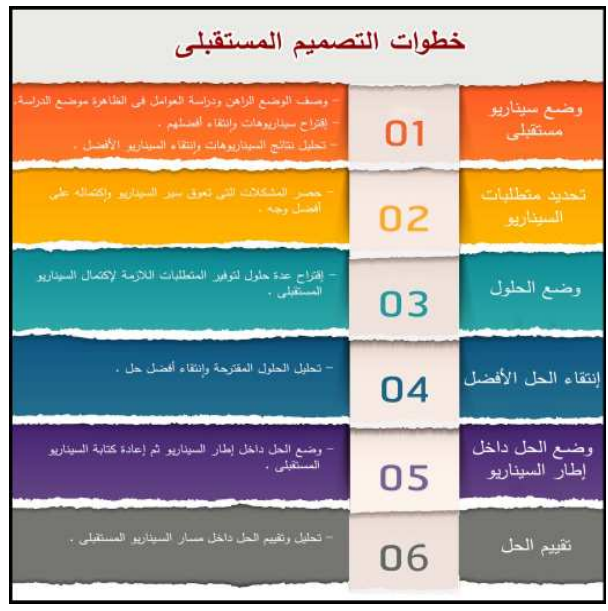

شكل (IV) خطوات التصميم المستقبلي 


\section{ع. دراسات حالة توضح هفهوم التصميم المستقبلي التفاعلى :}

Fـاـ محطة الاتصال Float Base Station

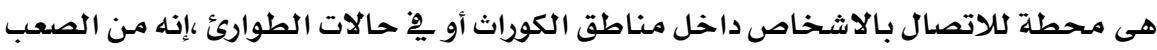

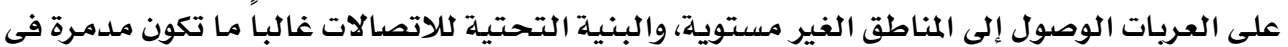

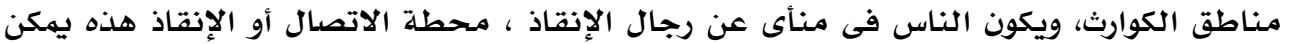

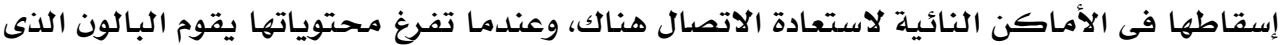

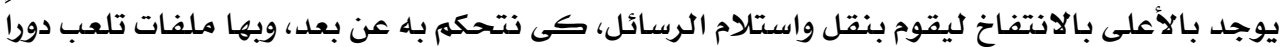

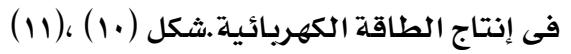

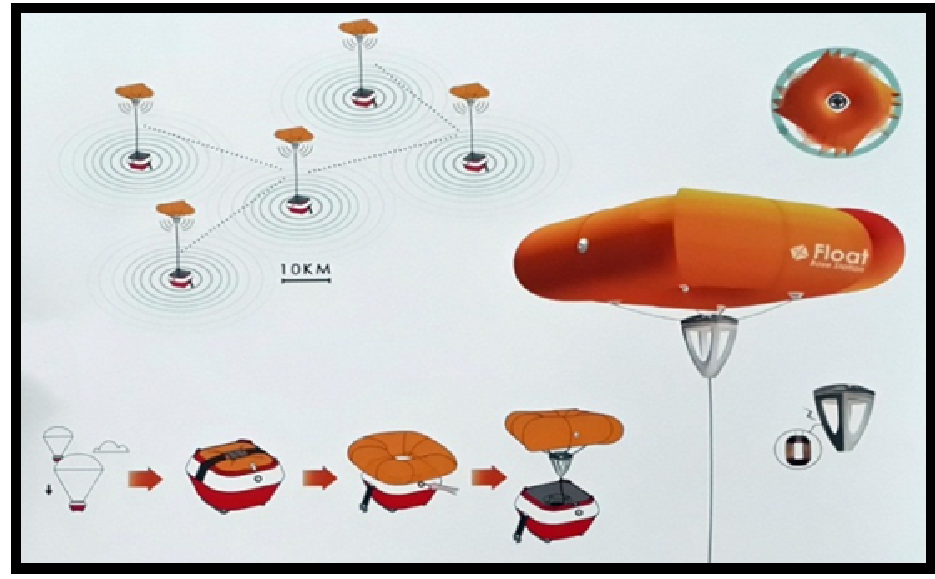

Fكل ( م) خطوات تشغيل محطة الاتصال Float Base Station

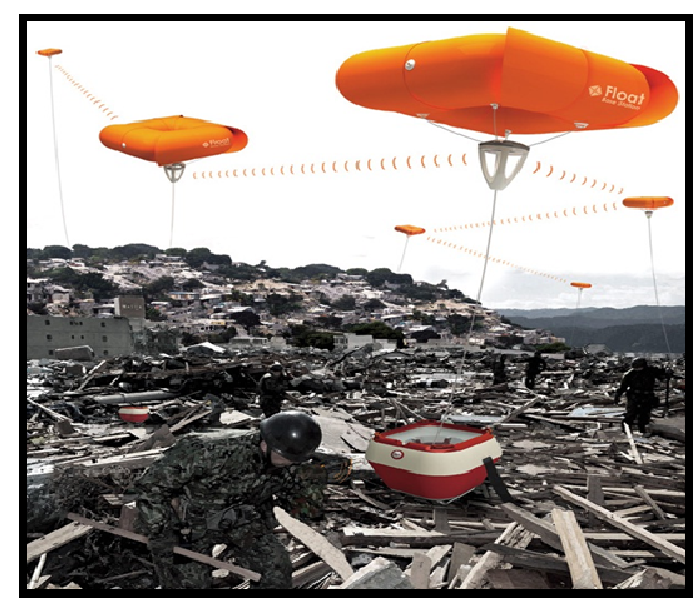

شكل (11) محطة الاتصال Float Base Station فى وضع الاستخدام 
عـrـ لوحة مفاتيح puzzle keyboard تتميز لوحلة المفاتيح puzzle keyboard هذه بأنه يمكن ترتيبها حسب رغبـة المستخدم،

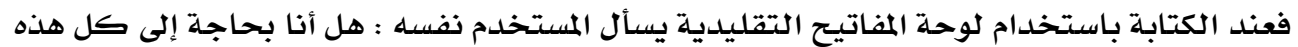

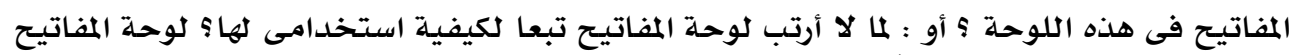

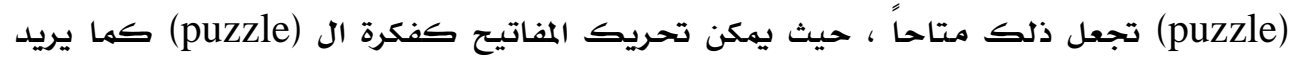

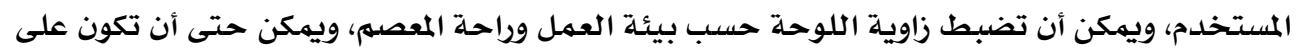

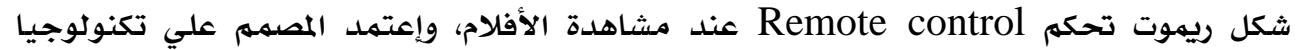

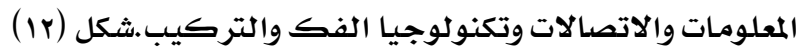

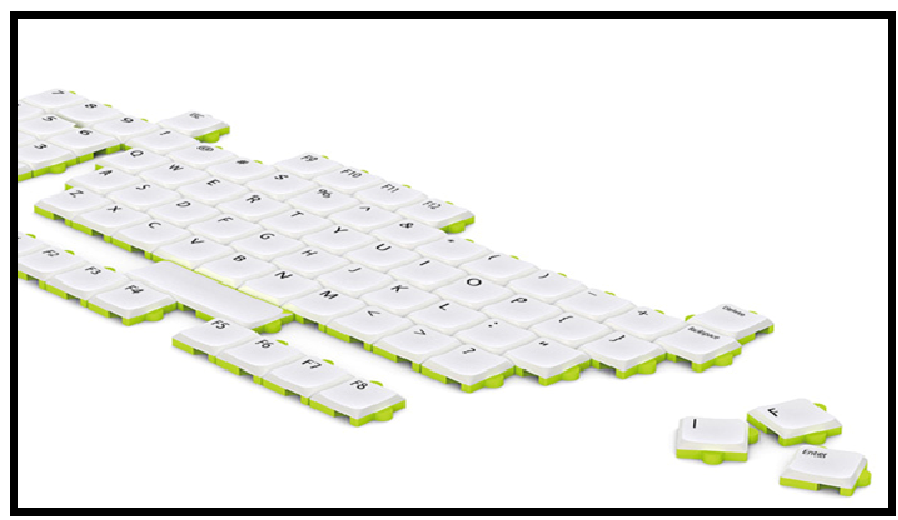

شكل (r) ) لوحة مفاتيح تفاعلية تتناسب مع رغبة المستخدم

كـrـ تذكرة للتذكير Reminding ticket، لشركة Lite on technology

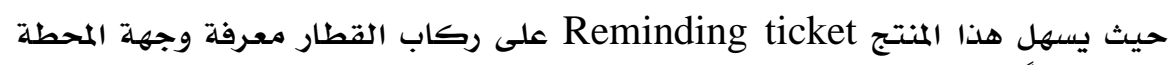

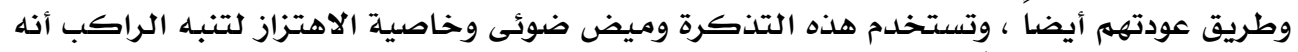

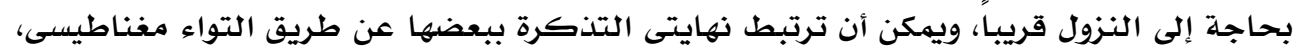

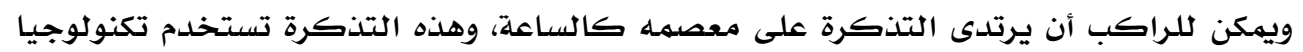

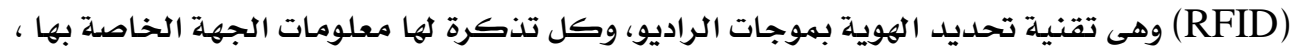

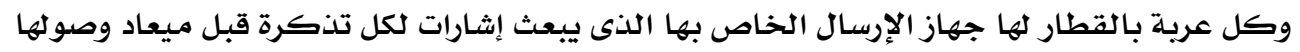

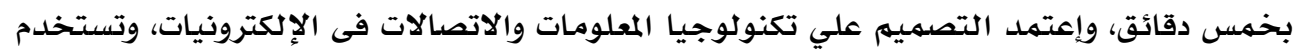

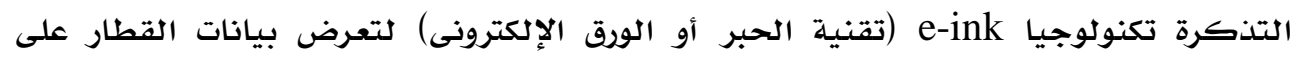

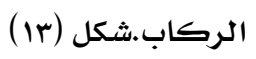




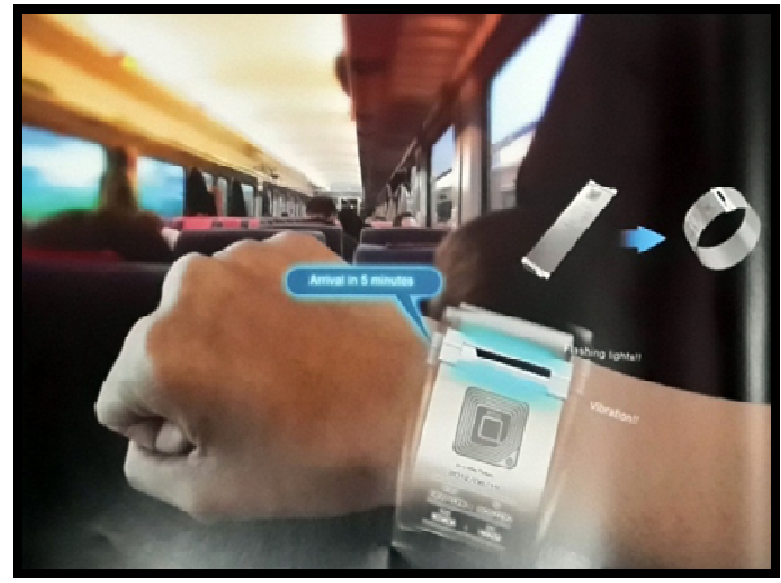

شكل (r) تذكرة للتذكير تفاعلية

Zipper

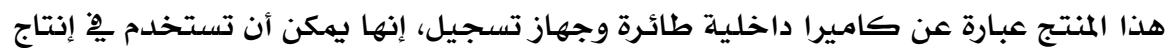
الأفلام، وفِ المراقبـة، ولعمليات التفتيث الأمنية، والتصوير يِ شبكات الصرف الصحي، ولمراقبة الأطفال يف المنزل، ويتم التحكم بهذه الكاميرا بإثنين من المحركات الكهريائية الدقيقة مـع مـراوح بواسطة معالج processor) ويهكن تعيين مسـار الحركة والسـرعة وبشكل تفاعلي عبر عصا التحكم أو جهاز التحكم عن بعد، وتنقل الصور المسجلة ومزيد من المعلومات لاسلكيا إلى أجهزة أخرى مثل أجهزة الكمبيوتر أو الهواتف الذكية، واعتمد التصهيمر علي تكنولوجيا الاتصالات والإلكترونيات .

شكل(1)

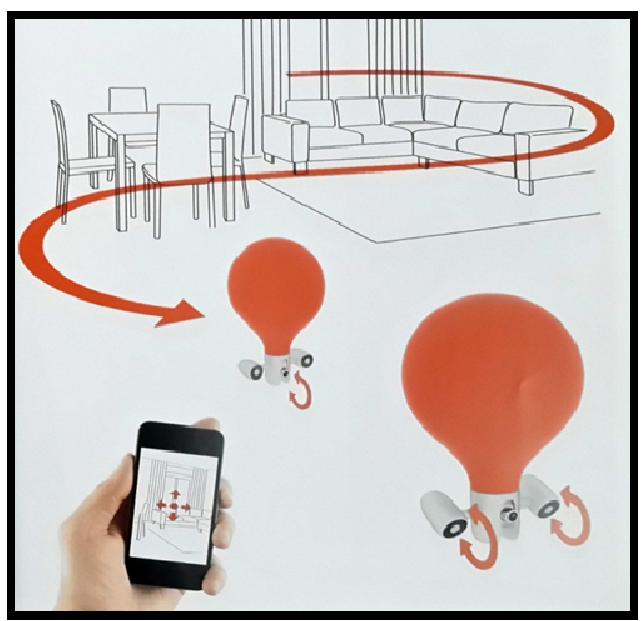

شكل (ع) جهاز Zipper كاميرا تفاعلية 
كـهـ شبكات إضاءة كثيفة Lumigrids

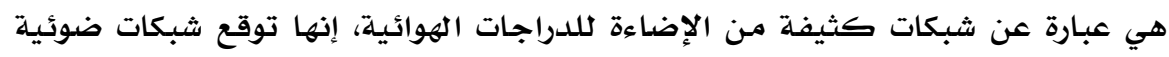

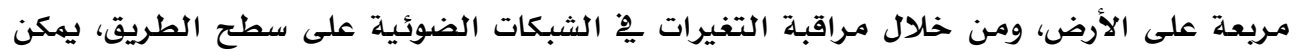

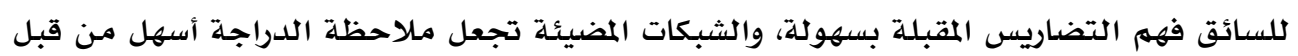

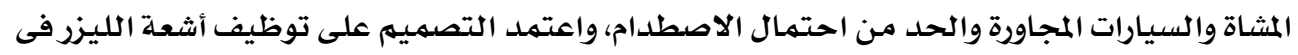
تكوين شبكات إضاءة .شكل (10)
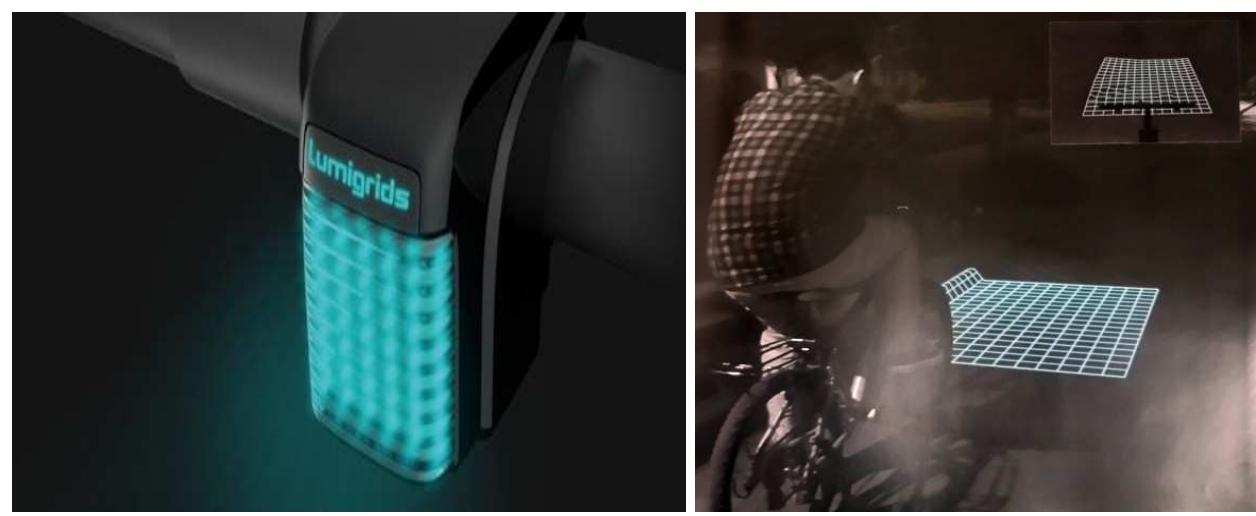

شكل (10) شبكات إضاءة كثيفة Lumigrids

الإنـاقشتة :

تبنى البـحث ثلاثة محاور قامت عليها الدراسـة وهذة المحاور هى :

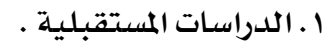

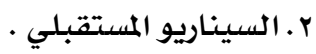

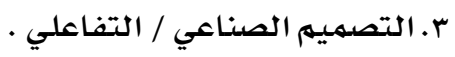

حيث تبين من دراسة هذه العوامل أن السيناريو المستقبلي - وهو من أهـم منـاهج الدراسـات

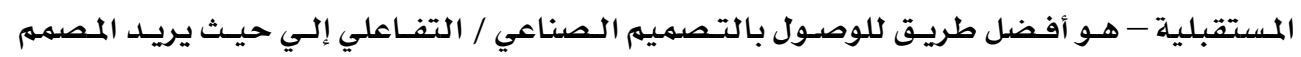

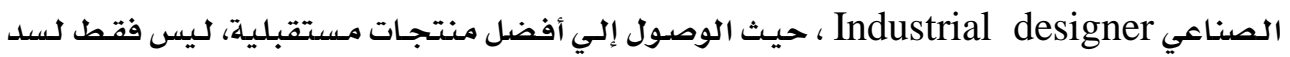

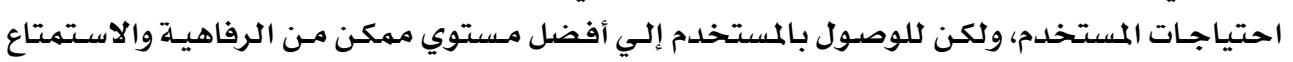

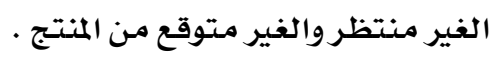

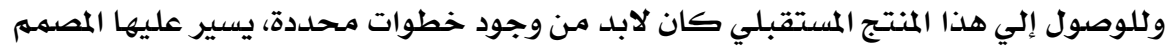

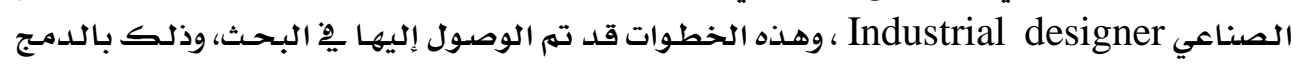

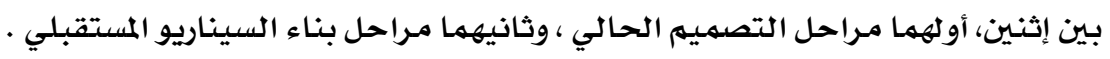




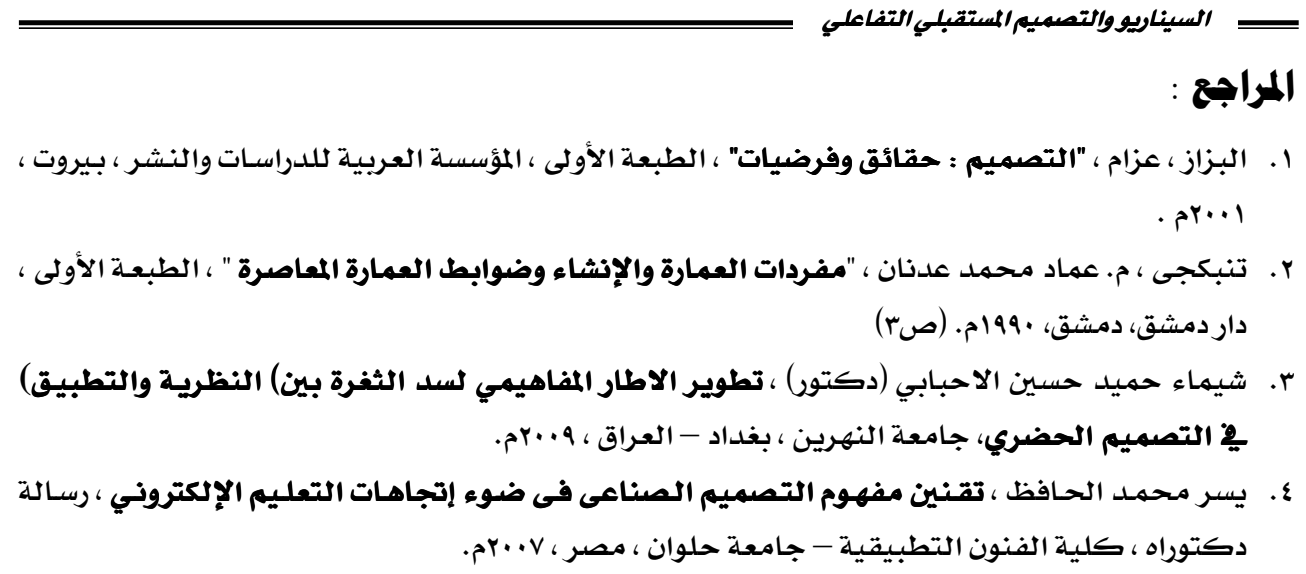

5. Desmet, P.M.A. (2003). A multilayeredmodel of product emotions. The Design Journal. In press

6. https://www.basingstoke.gov.uk/content/doclib/634.pdf

7. http://www.fwasl.com/interaction-design/

8. http://www.idsa.org/sites/default/files/2002_Kim\%20Boradkar.pdf

9. https://www.uop.edu.jo/download/research/members/230_3289_Dr.E.pdf 
Scenario and interactive Future design

\section{Abstract}

Future studies have techniques (methods), The most important is future scenarios technique, We can Deriving from it Many of the predictive future design Concepts, So research care showed us how to use science of Future Studies as a Reference guide in the development of the concept expectant future design ideas,and this concept is expectedly for the designer, but unexpectedly for the user, in accepting his Desires and ambitions, and these concepts are exciting, unconventional and can be applied in the future, Because it is measured on the wishes of the user commensurate with the future and concept of design here in general, and on the industrial and interactive design in particular.

The word "scenario" an Italian word, derived from the word "Sina" Scena, which meens sight. It has popularized the use of that word, in Europe, in the nineteenth century; and moved to the rest of the world, then. Its Use remained confined to the artwork, even the future science emerged in the second half of the twentieth century; And could not find a word to express the meaning of future planning, but the word "scenario". Which can be described as a product of modern science is based mainly on the feasibility study, Scenario mainly depends on the system of programming and stored data and which is constantly updated according to changes in all fields. It can also be defined as a description of the future situation it includes how to get to this situation, taking into account the current and possible factors for the case studied .Research problem illustrate the future design and building a scenario which is related to the field of future studies and the supply of industrial designer / interactive design considerations own future in the light of the changes in the future, located on the industrial design in the context of interactive design. The research aims to build a 
documented knowledge about how to elicit the design concept for the future. And insight to build future scenarios are valid in all the expected probability work on product development in the light of future studies and determine the options according to the expected variables. It may be "flexible", on the basis of aim options that determines alternative minimum forbidden missed, and alternative Which must be accessible. There are many Options in this case, reduced to the smallest number possible. The research hypotheses based on, if possible, activating the role of the future scenario and taking into account all the variables expected impact on the phenomenon under study will result in a future design concepts of a special character can be implemented at any stage in the future,then Future design concepts prove their worth, and accepted with the wishes and needs of the consumer. Research methodology relies on deductive approach. 